\title{
Tryptophan, Kynurenine and Kynurenic Acid Concentrations in Milk and Serum of Dairy Cows with Prototheca Mastitis
}

\author{
Mariola Bochniarz ${ }^{1}$, Tomasz Piech ${ }^{1}$, Tomasz Kocki ${ }^{2}$ (D), Mateusz Iskra ${ }^{3}$, Henryk Krukowski ${ }^{4}$ (D) \\ and Tomasz Jagielski ${ }^{3, *(1)}$
}

1 Department and Clinic of Animal Reproduction, Faculty of Veterinary Medicine, University of Life Sciences, Gleboka 30, 21-612 Lublin, Poland; mariola.bochniarz@up.lublin.pl (M.B.); tomasz.piech@up.lublin.pl (T.P.)

2 Department of Experimental and Clinical Pharmacology, Medical University of Lublin, Jaczewskiego 8b, 20-090 Lublin, Poland; tomasz.kocki@umlub.pl

3 Department of Medical Microbiology, Institute of Microbiology, Faculty of Biology, University of Warsaw, I. Miecznikowa 1, 02-096 Warsaw, Poland; m.iskra@biol.uw.edu.pl

4 Department of Animal and Environmental Hygiene, University of Life Sciences in Lublin, Akademicka 13, 20-950 Lublin, Poland; henryk.krukowski@up.lublin.pl

* Correspondence: t.jagielski@biol.uw.edu.pl

check for updates

Citation: Bochniarz, M.; Piech, T.; Kocki, T.; Iskra, M.; Krukowski, H.; Jagielski, T. Tryptophan, Kynurenine and Kynurenic Acid Concentrations in Milk and Serum of Dairy Cows with Prototheca Mastitis. Animals 2021 11, 3608. https://doi.org/10.3390/ ani11123608

Academic Editors: Hasitha Priyashantha and Janak Vidanarchchi

Received: 22 November 2021 Accepted: 14 December 2021 Published: 20 December 2021

Publisher's Note: MDPI stays neutral with regard to jurisdictional claims in published maps and institutional affiliations.

Copyright: (c) 2021 by the authors. Licensee MDPI, Basel, Switzerland. This article is an open access article distributed under the terms and conditions of the Creative Commons Attribution (CC BY) license (https:// creativecommons.org/licenses/by/ $4.0 /)$.
Simple Summary: Bovine mastitis continues to be a leading cause of heavy economic losses in the dairy industry worldwide. Among a broad spectrum of infectious agents implicated in this pathology are unicellular, achlorophyllous microalgae of the genus Prototheca. The prevalence of mastitis due to Prototheca algae is currently increasing. The aim of this work was to explore a possible association of the kynurenine pathway of tryptophan metabolism with Prototheca mastitis. The authors were eager to know whether metabolites of tryptophan degradation can be used as markers of the protothecal bovine mastitis. Both tryptophan and its metabolite kynurenine occurred at a significantly lower level in the milk of cows with mastitis compared to healthy animals. Whereas the activity of indoleamine 2,3-dioxygenase, a key enzyme of tryptophan catabolism, was significantly higher in milk of mastitic cows compared to control animals. It was thus concluded that low values of tryptophan and kynurenine concentrations or elevated indoleamine 2,3-dioxygenase activity in milk samples can be used as markers of mastitis due to Prototheca spp.

Abstract: The aim of this work was to investigate serum and milk levels of tryptophan (TRP), kynurenine (KYN), and kynurenic acid (KYNA), as well as the activity of indoleamine 2,3-dioxygenase (IDO) in cows with mastitis due to Prototheca algae. The study was prompted by previous research showing a link between the KYN pathway of TRP metabolism and bovine mastitis of bacterial etiology. The study was carried out over a 2-year period (2018-2019) and included quarter milk and serum samples collected from six dairy herds in Poland. The samples were obtained from healthy cows and cows with Prototheca mastitis of either clinical and subclinical manifestation, as determined upon direct measurement of the somatic cell count or indirectly by performing a California Mastitis Test on suspected quarters. Both TRP and KYN concentrations were significantly lower in milk of mastitic cows compared to healthy animals ( 0.8 vs. $8.72 \mu \mathrm{M}, p=0.001 ; 0.07$ vs. $0.32 \mu \mathrm{M}, p=0.001$, respectively). The difference in TRP and KYN concentrations in the sera of the two animal groups was much less pronounced ( 25.55 vs. $27.57 \mu \mathrm{M}, 3.03$ vs. $3.56 \mathrm{nM}$, respectively). The concentration of KYNA was almost at the same level in milk (1.73 vs. $1.70 \mathrm{nM})$ and in serum ( $80.47 \mathrm{vs.} 75.48 \mathrm{nM})$ of both mastitic and healthy cows. The data showed that the level of TRP and its metabolites in serum was conspicuously higher compared to milk in all cows under the study. The activity of IDO was significantly higher in milk of cows with Prototheca mastitis compared to healthy animals (71.4 vs. $40.86, p<0.05)$, while in serum it was pretty much the same $(135.94$ vs. $124.98, p>0.05)$. The IDO activity differed significantly between serum and milk both for mastitic (135.94 vs. 71.4, $p<0.05)$ and healthy cows (124.98 vs. $40.86, p<0.001)$. In conclusion, low values of TRP and KYN concentrations or elevated IDO activity in milk samples might be used as markers of mastitis due to infectious causes, including Prototheca spp. 
Keywords: cows; mastitis; Prototheca spp.; tryptophan; kynurenine; IDO

\section{Introduction}

Tryptophan (TRP) belongs to the group of nutritionally essential, exogenous amino acids and plays many important roles in animals and humans [1-3]. The activity of TRP is multidirectional. One of its pivotal functions is as a substrate for protein synthesis. Supplementation with TRP clearly enhances feed utilization, and thus boosts livestock productivity [4-6]. TRP-deficient diet leads to depressed body weight gain, lowered food intake, and an overall metabolic disturbance, which makes an animal more prone to infections and other ailments, thus increasing morbidity and mortality among the herds [3,7-9]. TRP has also been shown to counteract the stress response in animals, serving as a precursor of such important neuroactive molecules as serotonin and melatonin $[10,11]$.

TRP undergoes several metabolic pathways occurring mainly in liver [2,5]. In animals, as in humans, only around $1 \%$ of TRP is used for protein synthesis. Likewise, a very small portion $(<5 \%)$ of the amino acid is hydrolysed to 5-hydroxytryptophan, leading to the formation of serotonin, and subsequently melatonin, responsible for regulating mental health and circadian rhythms, respectively [12,13]. In contrast, more than $90 \%$ of TRP is metabolized via the kynurenine pathway (KP), with two enzymes, namely indoleamine 2,3-dioxygenase (IDO) and TRP 2,3-dioxygenase (TDO), catalyzing the first step of the pathway $[14,15]$. A key metabolite in KP is L-kynurenine (L-KYN, further in the text referred to as $\mathrm{KYN}$ ), which is a substrate for further metabolic transformations yielding a myriad of biologically active compounds. The KP metabolites, collectively referred to as kynurenines, have been demonstrated to be involved in many physiological and pathological processes [16]. Kynurenines have been shown to induce anti-inflammatory responses in the course of various infections, including bovine mastitis [15,17-20].

Mastitis is a multi-factorial disease, in which the pathogen, the host, and the environment are at a constant interplay with each other, determining the type and severity of the condition. Unicellular, achlorophyllous microalgae of the genus Prototheca have been increasingly implicated in the etiology of bovine mastitis [21-28]. These microorganisms are ubiquitously distributed in nature, with a clear predilection for humid and organicrich environments. Of 15 currently recognized species, only four have been reported as the causative agents of animal protothecosis, namely P. bovis (formerly P. zopfii gen. 2), P. blaschkeae, P. ciferrii (formerly P. zopfii gen. 1), and P. wickerhamii. [29]. The vast majority of Prototheca mastitis cases are due to $P$. bovis, but $P$. blaschkeae infections do also occur, even in an outbreak context [26,27,30-32].

Protothecal bovine mastitis typically occurs as a chronic disease, either symptomatic or clinically silent, with periods of flare-up and latency [22,33]. There are currently no standard treatment regimens for bovine mammary protothecosis. Upon laboratory drug susceptibility testing, the algae show high levels of resistance towards a variety of antimicrobial agents [34,35]. Although the disease is rarely life-threating, its persistence, drug resistance, and irreversible damage to the mammary gland tissue, leading to a decrease or complete loss of milk production, advocate culling as the only disease intervention strategy $[26,27]$.

The aim of the study was to investigate serum and milk concentrations of TRP, KYN, and kynurenic acid (KYNA), as well as to determine the IDO activity in cows with Prototheca mastitis and in healthy animals. The authors of this study were eager to know if and to what extent Prototheca mastitis affects KP, and whether the KP metabolites can be used as markers of this pathology.

The experiments reported here were prompted by our previous study which demonstrated a link between the kynurenine pathway of TRP metabolism and bovine mastitis of staphylococcal etiology [20]. 


\section{Materials and Methods}

\subsection{Dairy Farms and Animals}

The study was conducted over a two-year period (2018-2019) and included quarter milk samples (QMS) collected from 6 dairy herds (of 367 cows in total) in Eastern Poland (Lublin and Podlasie provinces).

The Holstein-Friesian cows were housed in brick-built, free-stall barns, with an average of $6.5 \mathrm{sq}$. $\mathrm{m}$. total space per cow and a minimum window-to-floor ratio of 1:15. The barns were naturally ventilated through adjustable sidewall and roof air inlets. The floor of the barns was covered with straw and the manure was removed manually or with mechanical separators at least once a day.

On all farms under the study, milking was done twice daily in a double-rowed milking parlour or with a milking pipeline. Before milking, the udders were washed with clean, warm water and dried with a separate cloth, and the teats were dipped in a disinfectant, typically an iodine-containing solution. The same solution was used for post-milking teat disinfection.

Winter feeding was based on maize silage, grass-hay silage, meadow hay, and individually formulated grain mixtures. The animals also received concentrated feed, as well as vitamin and mineral supplements. In the summer period, cows fed on pastures, but were also offered green forage and, in a smaller amount than in winter, maize silage, concentrates, and vitamin and mineral supplements. Feed was delivered to the pens using a feed truck. Water was available ad libitum from automatic drinking troughs.

The general health of the dairy herds was monitored through a scheduled routine and veterinary visits. For all breeding, artificial insemination was used.

\subsection{Sampling Procedures}

The quarter milk samples were collected from cows suspected of having mastitis, based on the veterinary clinical examination as per the results of the California Mastitis Test (CMT; Mastirapid, Vetoquinol Biowet, Poland). Scoring of the CMT results was performed according to Quinn et al. (2002) [36]. CMT-positive QMS were examined for microbiological growth and were tested for somatic cell count (SCC), essentially as

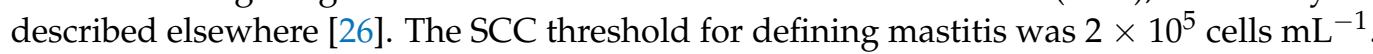
Clinical (CM) and subclinical (SCM) mastitis were defined as previously reported [26].

Milk sample collection procedures, culturing methods, and interpretative criteria of microbial growth were described essentially elsewhere [26]. Colonies suspected to be Protothec a spp. were subcultured on Sabouraud dextrose agar (SDA, Difco Laboratories, Detroit, MI, USA) and subjected to species identification, which included both phenotypic (morphological and auxanographic assays) and molecular methods, with the latter carried out as a PCR restriction-enzyme analysis (PCR-REA) assay of the partial CYTB gene [37].

\subsection{Study Group}

A total of 20 dairy cows were included as the study group. Comprised within this number were 10 cows identified as having Prototheca mastitis and 10 healthy (control) cows, chosen randomly among the herds investigated (i.e., 2 cows from each of the four herds and single cows from another two herds). The healthy status of control cows was supported by a lack of any clinical signs of mastitis, negative bacteriological examination, and SCC level of $<100,000$ cells $/ \mathrm{mL}$. For all animals, the complete blood cell (CBC) tests (incl. red blood cells, white blood cells, platelets, haemoglobin, and haematocrit) were performed using Scil ABC+ Vet Animal Hematology Analyzer (Horiba, Kyoto, Japan). The results of the CBC tests are provided in the Supplementary Table S1. 


\subsection{Measurements of TRP and Its Metabolites Concentrations in Milk and Serum}

TRP, KYN, and KYNA were analyzed by high-performance liquid chromatography (HPLC), according to the protocol of Zhao et al. (2010), with minor adjustments [38]. Briefly, to each milk and serum sample, $6 \% \mathrm{HClO}_{4}$ was added and the sample was centrifuged at $12,000 \times g$ for $30 \mathrm{~min}$ at $4{ }^{\circ} \mathrm{C}$. The resulting supernatant was used for HPLC with the Dionex P680 Pump, UltiMate 3000 Autosampler with column compartment (Sunnyvale, CA, USA). Agilent HC-C18(2) column $(250 \times 4.6 \mathrm{~mm}$ i.d.; $5-\mu \mathrm{m}$ particle size) was used coupled to RS Variable Wavelength UltiMate 3000 Detector (Dionex, Sunnyvale, CA, USA) set at wavelengths $250 \mathrm{~nm}$ for TRP, $365 \mathrm{~nm}$ for KYN, and RF 2000 Fluorescence Detector (Dionex) set at excitation wavelength of $348 \mathrm{~nm}$ and emission at $398 \mathrm{~nm}$ for KYNA determination. The mobile phase was a mixture of $20-\mathrm{mM} \mathrm{NaAc}, 5-\mathrm{mM} \mathrm{ZnAc}_{2}$, and $4 \%$ acetonitrile for which the flow rate was $1.0 \mathrm{~mL} / \mathrm{min}$. Control of the HPLC system and data collection were performed with the Chromeleon software (Dionex).

A full description and validation of the method is provided in the paper, by Zhao et al. (2010) [38].

IDO activity was calculated as a ratio by dividing the content of $\mathrm{KYN}$ (in $\mu \mathrm{M}$ multiplied by 1000) by that of TRP (in $\mu \mathrm{M})$ [39].

\subsection{Statistical Analysis}

Statistical methods were used to compare concentrations of TRP, KYN, and KYNA, as well as IDO activities in serum and milk of healthy cows and cows with Prototheca mastitis. Statistical parameters included the minimum and maximum values, median, mean, and standard deviation (SD). The Mann-Whitney test was applied for comparison between these parameters for two independent trials, since the Shapiro-Wilk test showed a nonnormal distribution of data. A value of $p<0.05$ was considered significant. All calculations were performed using the statistical package of IBM SPSS Statistics for Windows, version 24.0 (IBM, Armonk, NY, USA).

\section{Results}

Out of a total of 121 cows examined, 48 were CMT-positive. Among these, $4(8.3 \%)$ did not show any microbial growth upon culture, whereas the remaining $44(91.7 \%)$ were identified as having mastitis due to either bacteria (31 or 70.5\%; coagulase-negative Staphylococcus spp. (CNS)-15 or 34.1\%; Staphylococcus aureus-2 or $4.6 \%$; Streptococcus agalactiae - 1 or $2.3 \%$; Streptococcus dysgalactiae - 4 or $9.1 \%$; Streptococcus uberis-6 or $13.6 \%$; Escherichia coli-3 or $6.8 \%$ ) yeasts (Candida spp.-3 or $6.8 \%$ ) or Prototheca spp. (10; 22.7\%). In all Prototheca mastitis cases, $P$. bovis was the etiological agent. These cows came from all 6 farms under the study; four cows were single cases (a case per herd), whereas the other six represented clustered cases (i.e., two cows in one herd, and four cows in another herd were affected). Eight cows had subclinical mastitis, and the remaining two presented with a clinical disease. The SCC values in milk samples of these cows fell within a wide range of 406,000-10,000,000 cells / mL.

From all sick animals, 10 serum samples and 15 milk samples were collected (in 6 cows, Prototheca spp. were cultured from one quarter only, in 3 cows-from two quarters, and in one cow-from three quarters). One milk sample was heavily flaky, making assessment of TRP and kynurenine levels impossible. Thus, the results were obtained and presented for 14 milk samples.

TRP, KYN, and KYNA Concentrations in Milk and Serum of Cows with Prototheca Mastitis and Healthy Animals

TRP and KYN concentrations were significantly lower in the milk of cows with Prototheca mastitis compared to healthy animals ( 0.8 vs. $8.72 \mu \mathrm{M}, p=0.001 ; 0.07$ vs. $0.32 \mu \mathrm{M}$, $p=0.001$, respectively) (Figure 1A). However, there was no statistically significant difference in TRP and KYN concentrations in sera of animals from the two groups ( 25.55 vs. $27.57 \mu \mathrm{M}$, 3.03 vs. $3.56 \mathrm{nM}$, respectively) (Figure 1B). The concentration of KYNA was almost at the 
same level in milk (1.73 vs. $1.70 \mathrm{nM})$ and in serum ( $80.47 \mathrm{vs.} 75.48 \mathrm{nM})$ of both mastitic and healthy cows (Figure 1).

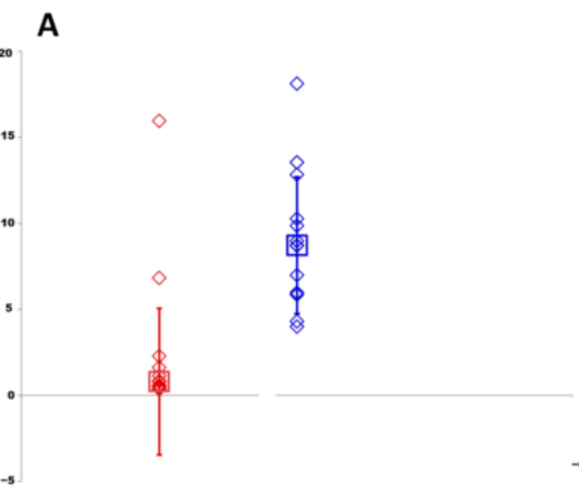

$\operatorname{TRP}[\mu \mathrm{M}]$

B

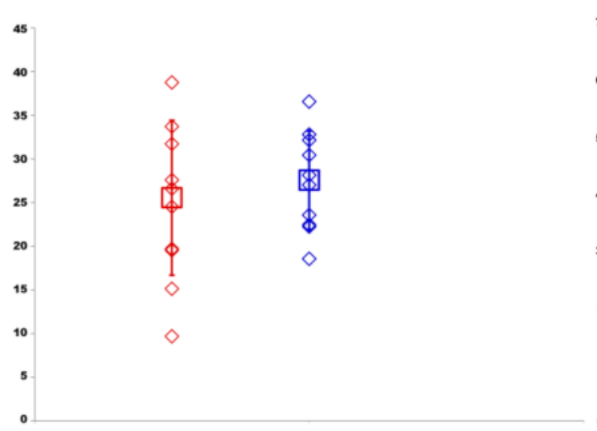

$\operatorname{TRP}[\mu \mathrm{M}]$
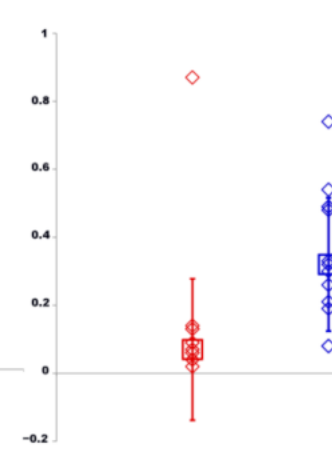

$\mathrm{KYN}[\mu \mathrm{M}]$

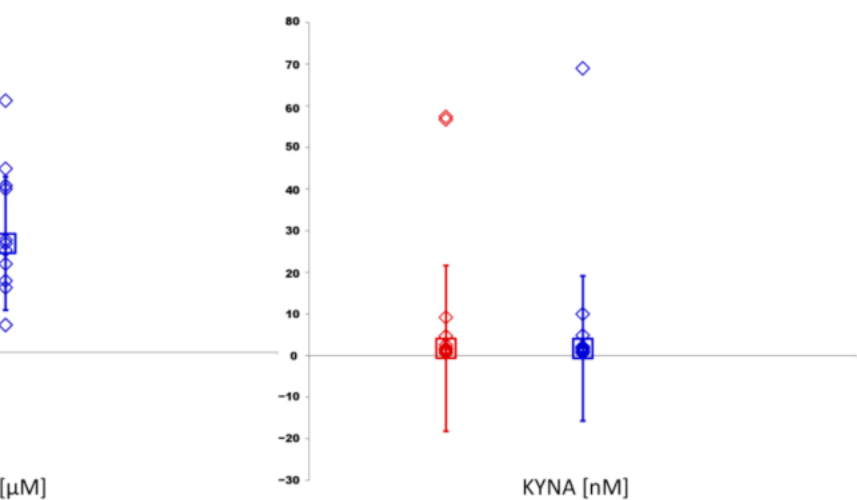

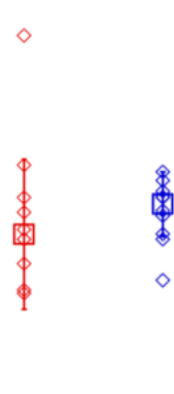

$\mathrm{KYN}[\mu \mathrm{M}]$

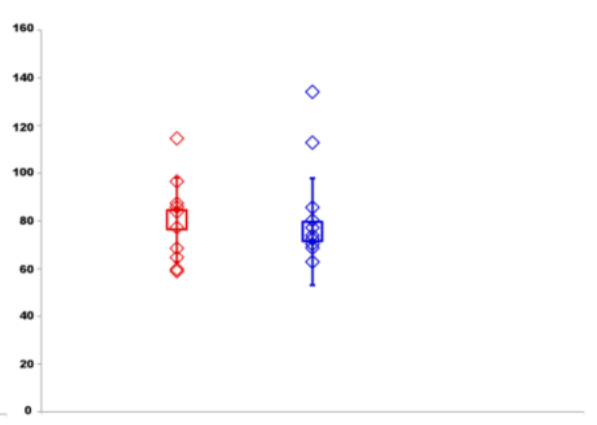

KYNA [nM]

Prototheca mastitis

Control

Figure 1. TRP, KYN, and KYNA concentrations in milk (A) and serum (B) of cows with Prototheca mastitis and control animals. The median and standard deviation are represented as squares and vertical lines, respectively.

The data show that the levels of TRP and its metabolites in serum were conspicuously higher compared to milk in all cows under the study. Serum TRP levels in healthy cows ranged from 18.56 to $36.55 \mu \mathrm{M}$ (median $27.57 \mu \mathrm{M}$ ) and were several times higher than in the milk of these animals (3.99-18.11 $\mu \mathrm{M}$, median $8.72 \mu \mathrm{M}, p=0.001)$. Likewise, in mastitic cows, a significant difference in median TRP concentrations in serum and milk was noted ( 25.55 vs. $0.8 \mu \mathrm{M}, p<0.001)$. The same observation was made for the levels of TRP metabolites, i.e., KYN and KYNA. Both in the group of healthy and diseased cows, the levels of KYN (3.56 vs. $0.32 \mu \mathrm{M}, p<0.001 ; 3.03$ vs. $0.07, p<0.001$, respectively) and KYNA (75.48 vs. $1.70 \mathrm{nM}, p<0.001 ; 80.47$ vs. $1.73 \mathrm{nM}, p<0.001$, respectively) were significantly higher in serum than in milk.

IDO activity, determined as KYN/TRP ratio, was significantly higher in the milk of cows with mastitis compared to healthy cows (71.4 vs. $40.86, p<0.05)$. Whereas, IDO activity in sera of cows of the two groups was almost at the same level (135.94 vs. 124.98, $p>0.05)$. The IDO activity differed significantly between serum and milk both for mastitic (135.94 vs. $71.4, p<0.05)$ and healthy cows (124.98 vs. 40.86, $p<0.001)$. (Figure 2$)$. 
A

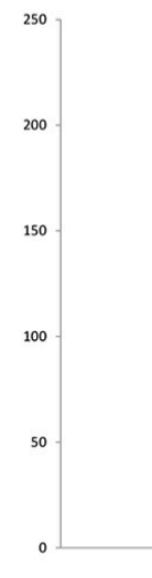

B

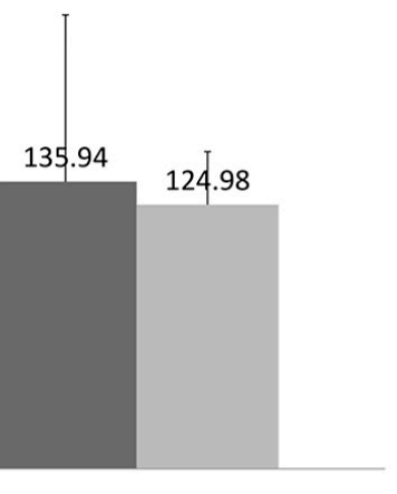

IDO $[\mathrm{KYN}(\mu \mathrm{M}) / \mathrm{TRP}(\mu \mathrm{M}) \times 1000]$

Prototheca mastitis $\quad$ Control

Figure 2. IDO activity in milk (A) and serum (B) of cows with Prototheca mastitis and control animals. Numbers above the bars are median values, while vertical lines represent standard deviation.

\section{Discussion}

This study investigated, for the first time, the concentrations of TRP, KYN, KYNA, and the activity of IDO in serum and milk of cows with Prototheca mastitis.

One of the processes regulating the course and severity of inflammation is the activation of TRP metabolism via the KP $[14,17,40]$. While IDO plays only a minor role in TRP metabolism under physiological conditions, the KP pathway is strongly activated in response to cytokines secreted during inflammation $[15,40,41]$.

In our study, a significant increase in IDO activity in milk was observed during the Prototheca mastitis infection. The IDO activity in Prototheca-contaminated milk was nearly two-fold that in milk from healthy cows. At the same time, the serum IDO activities were quite the same in both mastitic and control animals. This suggests that the inflammatory process induced by the algae occurs locally in the udder and does not trigger a systemic immune response. This is further supported by the lack of any general symptoms in cows with Prototheca mastitis. Significantly, the high IDO activity in milk of mastitis cows correlated with a significant increase in their milk SCCs. The mean SCC value calculated for milk from Prototheca-infected udders was 4,689,933 cells, $\mathrm{mL}^{-1}$, being over 40 -fold higher compared to a threshold limit for milk acceptance, typically set at $<100,000$ cells $/ \mathrm{mL}$ [42] This indicates increased migration of leukocytes, mainly neutrophils and macrophages to the inflammatory focus within the mammary gland.

According to the literature, the expression of IDO in the immune response cells, and macrophages in particular, is induced upon different stimuli, including pro-inflammatory cytokines $[3,43]$. Interferon $\gamma(\mathrm{IFN}-\gamma)$ is believed to be the most potent activator of this enzyme [44]. Consequently, stimulation of IDO activity shifts TRP metabolism towards the $\mathrm{KP}$, leading to KYN production, and thereby significantly reducing the concentration of available TRP. This, as repeatedly evidenced, inhibits growth of many microbial pathogens including intracellular parasites (Toxoplasma gondii, Plasmodium sp.), bacteria (Pseudomonas aeruginosa, Chlamydia, Rickettsia, Streptococcus sp., Staphylococcus sp.), and viruses (Herpes simplex virus) [40,45-49].

In our study, a clear relationship was found between IDO activation and TRP levels. Along with a significant increase of the IDO activity in milk, over a 10-fold lower level of TRP was recorded in the milk of mastitis cows compared to the control group. Still, at the serum level, no changes in the TRP concentrations were noted between healthy and diseased cows, since in the latter no IDO activation occurred. One may point to 
generally much higher values of TRP (and its metabolites) concentrations in sera than in milk samples. This is what was observed in previous studies. The TRP levels in serum consistently surpassed those in milk, irrespective of the physiological state of the udder [20,50].

The difference between the serum and milk level of TRP is plausibly due to an extensive use of this (and other) amino acid for milk protein synthesis in the mammary gland tissue, and the production of gluconeogenic and ketogenic precursors [50]. Captivatingly, the TRP concentration in milk of healthy cows was about $30 \%$ of its level in serum, while in the Prototheca mastitis cows, the level of TRP in milk was merely $3 \%$ of that found in serum.

Finally, the results of this study indicate that in the course of mastitis and KP activation, TRP, or at least some of its amount, can be metabolized in ways other than the normal healthy conditions. This is illustrated by the milk levels of KYN in mastitis and control cows. Among the latter, the KYN concentrations were 4-fold higher compared to mastitis animals. It is thus possible that KYN, which is the first product of increased TRP catabolism, undergoes an accelerated transformation (into more downstream metabolites) in the KP. Depending on the degree of cell specialization, KYN metabolism occurs through three branches, leading to the production of either 3-hydroxy-kynurenine (3-OH-KYN), anthranilic acid (AA) or KYNA $[17,49,51]$. In this study, the KYNA concentration in milk of mastitis cows equaled that in healthy animals. Altogether, it seems likely that KYN was metabolized via an alternative to KYNA-yielding catabolic pathway.

A limitation of the study was a relatively small sample size. Despite being on the rise, Prototheca mastitis is not as common as bacterial udder infections. Still, providing more Prototheca-positive milk samples would significantly improve the accuracy of the analysis and strengthen our conclusions.

In summary, the present work adds to very scanty research on Prototheca mastitis pathogenesis, providing details of one of the aspects of cellular response to Protothecainduced inflammation of the mammary gland tissue. A significant increase of IDO activity in the milk of mastitis cows was closely related to a decrease of TRP and KYN concentrations. These findings may have important implications for diagnosing Prototheca mastitis, especially in cases without general symptoms or changes in milk or the mammary gland. Here, the activation of the KYN pathway and its metabolites might be used as markers of mastitis due to Prototheca spp. The mechanism might be the same as with other (bacterial) mastitis pathogens. Upon infection, a local (intramammary) immunological response develops, leading to an increased number of leukocytes and macrophages at the site of inflammation. These cells release excessively IDO-inducing pro-inflammatory cytokines, which in turn diverts TRP towards the kynurenine pathway.

Supplementary Materials: The following are available online at https: / www.mdpi.com/article / 10.3390/ani11123608/s1. Table S1: Complete blood test cel results for both cows with Prototheca mastitis and healthy (control) animals.

Author Contributions: Conceptualization, M.B. and T.J.; methodology, M.B., T.K., T.P., H.K. and T.J.; software, M.I.; validation, M.B., T.K. and T.P.; formal analysis, M.B., T.K., T.P., H.K.; investigation, M.B., T.K., T.P., H.K.; resources, T.J.; data curation, M.B.; writing-original draft preparation, M.B.; writing-review and editing, T.J.; visualization, M.I.; supervision, M.B.; project administration, T.J.; funding acquisition, T.J. All authors have read and agreed to the published version of the manuscript.

Funding: The study was financed by a grant from the National Science Centre, within the "SONATA" programme (Kraków, Poland; contract no.: 2014/15/D/NZ7/01797).

Institutional Review Board Statement: All experimental procedures on animals, carried out in this project, were considered by the Local Ethics Committee for Animal Experimentation in Lublin as routine veterinary services for dairy cows, and as such did not fall under the regulations of the Animal Experimentation Act of 15 January 2015 (Dz. U. 2015 poz. 266), thereby being exempt from needing approval from the local ethics committees for the protection of animals used for scientific purposes. Consequently, the study was performed in agreement with Polish law (Dz. U. 2015 poz. 
266), as well as the European Union regulations of the Directive 2010/63/EU on the protection of animals used for scientific purposes.

Informed Consent Statement: Not applicable.

Data Availability Statement: None of the data were deposited in an official repository.

Conflicts of Interest: The authors declare no competing interest.

\section{References}

1. Moffett, J.R.; Namboodiri, A. Tryptophan and the immune response. Immunol. Cell Biol. 2003, 81, 247-265. [CrossRef] [PubMed]

2. Le Floc'H, N.; Seve, B. Biological roles of tryptophan and its metabolism: Potential implications for pig feeding. Livest. Sci. 2007, 112, 23-32. [CrossRef]

3. Bai, M.; Liu, H.; Xu, K.; Oso, A.O.; Wu, X.; Liu, G.; Tossou, M.C.B.; Al-Dhabi, N.A.; Duraipandiyan, V.; Xi, Q.; et al. A review of the immunomodulatory role of dietary tryptophan in livestock and poultry. Amino Acids 2017, 49, 67-74. [CrossRef]

4. Cortamira, N.; Seve, O.B.; Lebreton, Y.; Ganier, P. Effect of dietary tryptophan on muscle, liver and whole-body protein-synthesis in weaned piglets-relationship to plasma-insulin. Br. J. Nutr. 1991, 66, 423-435. [CrossRef] [PubMed]

5. Yao, K.; Fang, J.; Yin, Y.L.; Feng, Z.M.; Tang, Z.R.; Wu, G. Tryptophan metabolism in animals: Important roles in nutrition and health. Front. Biosci. 2011, 3, 286-297.

6. Ruan, Z.; Yang, Y.; Wen, Y.; Zhou, Y.; Fu, X.; Ding, S.; Liu, G.; Yao, K.; Wu, X.; Deng, Z.; et al. Metabolomic analysis of amino acid and fat metabolism in rats with L-tryptophan supplementation. Amino Acids 2014, 46, 2681-2691. [CrossRef]

7. Melchior, D.; Sève, B.; Le Floch, N. Chronic lung inflammation affects plasma amino acid concentrations in pigs. J. Anim. Sci. 2004, 82, 1091-1099. [CrossRef] [PubMed]

8. Wu, G.Y. Amino acids: Metabolism, functions, and nutrition. Amino Acids 2009, 37, 1-17. [CrossRef] [PubMed]

9. Laeger, T.; Görs, S.; Metges, C.; Kuhla, B. Effect of feed restriction on metabolites in cerebrospinal fluid and plasma of dairy cows. J. Dairy Sci. 2012, 95, 1198-1208. [CrossRef] [PubMed]

10. Kollmann, M.T.; Locher, M.; Hirche, F.; Eder, K.; Meyer, H.H.; Bruckmaier, R.M. Effects of tryptophan supplementation on plasma tryptophan and related hormone levels in heifers and dairy cows. Domest. Anim. Endocrinol. 2008, 34, 14-24. [CrossRef]

11. Le Floc'H, N.; Melchior, D.; Sève, B. Dietary tryptophan helps to preserve tryptophan homeostasis in pigs suffering from lung inflammation1. J. Anim. Sci. 2008, 86, 3473-3479. [CrossRef] [PubMed]

12. Esteban, S.; Nicolaus, C.; Garmundi, A.; Rial, R.V.; Rodriguez, A.B.; Ortega, E.; Ibars, C.B. Effect of orally administered Ltryptophan on serotonin, melatonin, and the innate immune response in the rat. Mol. Cell Biochem. 2004, 267, 39-46. [CrossRef] [PubMed]

13. Höglund, E.; Øverli, Ø.; Winberg, S. Tryptophan Metabolic Pathways and Brain Serotonergic Activity: A Comparative Review. Front. Endocrinol. 2019, 10, e158. [CrossRef]

14. Fatokun, A.A.; Hunt, N.H.; Ball, H.J. Indoleamine 2,3-dioxygenase 2 (IDO1) and the kynurenine pathway: Characteristics and potential roles in health and disease. Amino Acids 2013, 45, 1319-1329. [CrossRef]

15. Poormasjedi-Meibod, M.-S.; Jalili, R.B.; Hosseini-Tabatabaei, A.; Hartwell, R.; Ghahary, A. Immuno-Regulatory Function of Indoleamine 2,3 Dioxygenase through Modulation of Innate Immune Responses. PLoS ONE 2013, 8, e71044.

16. Cervenka, I.; Agudelo, L.Z.; Ruas, J.L. Kynurenines: Tryptophan's metabolites in exercise, inflammation, and mental health. Science 2017, 357, 6349. [CrossRef]

17. Narui, K.; Noguchi, N.; Saito, A.; Kakimi, K.; Motomura, N.; Kubo, K.; Takamoto, S.; Sasatsu, M. Anti-infectious Activity of Tryptophan Metabolites in the L-Tryptophan-L-Kynurenine Pathway. Biol. Pharm. Bull. 2009, 32, 41-44. [CrossRef]

18. Nino-Castro, A.; Abdullah, Z.; Popov, A.; Thabet, Y.; Beyer, M.; Knolle, P.A.; Domann, E.; Chakraborty, T.; Schmidt, S.V.; Schultze, J. The IDO1-induced kynurenines play a major role in the antimicrobial effect of human myeloid cells against Listeria monocytogenes. Innate Immun. 2014, 20, 401-411. [CrossRef] [PubMed]

19. Harden, J.L.; Lewis, S.M.; Lish, S.R.; Suarez-Farinas, M.; Gareau, D.; Lentini, T.; Johnson-Huang, L.M.; Krueger, J.G.; Lowes, M.A. The tryptophan metabolism enzyme L-kynureninase is a novel inflammatory factor in psoriasis and other inflammatory diseases. J. Allergy Clin. Immunol. 2016, 137, 1830-1840. [CrossRef]

20. Bochniarz, M.; Kocki, T.; Dąbrowski, R.; Szczubiał, M.; Wawron, W.; Turski, W.A. Tryptophan, kynurenine, kynurenic acid concentrations and indoleamine 2,3-dioxygenase activity in serum and milk of dairy cows with subclinical mastitis caused by coagulase-negative staphylococci. Reprod. Domest. Anim. 2018, 53, 1491-1497. [CrossRef]

21. Buzzini, P.; Turchetti, B.; Facelli, R.; Baudino, R.; Cavarero, F.; Mattalia, L.; Mosso, P.; Martini, A. First large-scale isolation of Prototheca zopfii from milk produced by dairy herds in Italy. Mycopathologia 2004, 158, 427-430. [CrossRef] [PubMed]

22. Bueno, V.F.; de Mesquita, A.J.; Neves, R.B.; de Souza, M.A.; Ribeiro, A.R.; Nicolau, E.S.; de Oliveira, A.N. Epidemiological and clinical aspects of the first outbreak of bovine mastitis caused by Prototheca zopfii in Goias State, Brazil. Mycopathologia 2006, 161, 141-145. [CrossRef]

23. Osumi, T.; Kishimoto, Y.; Kano, R.; Maruyama, H.; Onozaki, M.; Makimura, K.; Ito, T.; Matsubara, K.; Hasegawa, A. Prototheca zopfii genotypes isolated from cow barns and bovine mastitis in Japan. Veter. Microbiol. 2008, 131, 419-423. [CrossRef]

24. Pieper, L.; Godkin, A.; Roesler, U.; Polleichtner, A.; Slavić, D.; Leslie, K.; Kelton, D. Herd characteristics and cow-level factors associated with Prototheca mastitis on dairy farms in Ontario, Canada. J. Dairy Sci. 2012, 95, 5635-5644. [CrossRef] [PubMed] 
25. Shahid, M.; Ali, T.; Zhang, L.; Hou, R.; Zhang, S.; Ding, L.; Han, D.; Deng, Z.; Rahman, A. Characterization of Prototheca zopfii genotypes isolated from cases of bovine mastitis and cow barns in China. Mycopathologia 2016, 181, 185-195. [CrossRef] [PubMed]

26. Jagielski, T.; Roeske, K.; Bakuła, Z.; Piech, T.; Wlazło, Ł.; Bochniarz, M.; Woch, P.; Krukowski, H. A survey on the incidence of Prototheca mastitis in dairy herds in Lublin province, Poland. J. Dairy Sci. 2019, 102, 619-628. [CrossRef]

27. Jagielski, T.; Krukowski, H.; Bochniarz, M.; Piech, T.; Roeske, K.; Bakuła, Z.; Wlazło, Ł.; Woch, P. Prevalence of Prototheca spp. on dairy farms in Poland-A cross-country study. Microb. Biotechnol. 2019, 12, 556-566. [CrossRef]

28. Park, H.-S.; Moon, D.C.; Hyun, B.-H.; Lim, S.-K. Short communication: Occurrence and persistence of Prototheca zopfii in dairy herds of Korea. J. Dairy Sci. 2019, 102, 2539-2543. [CrossRef] [PubMed]

29. Jagielski, T.; Bakuła, Z.; Gawor, J.; Maciszewski, K.; Dylag, M.; Nowakowska, J.; Gromadka, R.; Karnkowska, A. The genus Prototheca (Trebouxiophyceae, Chlorophyta) revisited: Implications from molecular taxonomic studies. Algal Res. 2019, 43, e101639. [CrossRef]

30. Marques, S.; Silva, E.; Kraft, C.; Carvalheira, J.; Videira, A.; Huss, V.A.R.; Thompson, G. Bovine Mastitis Associated with Prototheca blaschkeae. J. Clin. Microbiol. 2008, 46, 1941-1945. [CrossRef]

31. Ricchi, M.; De Cicco, C.; Buzzini, P.; Cammi, G.; Arrigoni, N.; Cammi, M.; Garbarino, C. First outbreak of bovine mastitis caused by Prototheca blaschkeae. Veter. Microbiol. 2013, 162, 997-999. [CrossRef] [PubMed]

32. Jagielski, T.; Lassa, H.; Ahrholdt, J.; Malinowski, E.; Roesler, U. Genotyping of bovine Prototheca mastitis isolates from Poland. Veter. Microbiol. 2011, 149, 283-287. [CrossRef] [PubMed]

33. Wawron, W.; Bochniarz, M.; Piech, T.; Łopuszyński, W.; Wysocki, J. Outbreak of protothecal mastitis in a herd of dairy cows in Poland. Bull. Veter. Inst. Pulawy 2013, 57, 335-339. [CrossRef]

34. Buzzini, P.; Turchetti, B.; Branda, E.; Goretti, M.; Amici, M.; Lagneau, P.-E.; Scaccabarozzi, L.; Bronzo, V.; Moroni, P. Large-scale screening of the in vitro susceptibility of Prototheca zopfii towards polyene antibiotics. Med. Mycol. 2008, 46, 511-514. [CrossRef] [PubMed]

35. Jagielski, T.; Buzzini, P.; Lassa, H.; Malinowski, E.; Branda, E.; Turchetti, B.; Polleichtner, A.; Roesler, U.; Lagneau, P.-E.; Marques, S.; et al. Multicentre Etest evaluation of in vitro activity of conventional antifungal drugs against European bovine mastitis Prototheca spp. isolates. J. Antimicrob. Chemother. 2012, 67, 1945-1947. [CrossRef]

36. Quinn, P.J.; Carter, M.E.; Markey, B.K.; Carter, G.R. Bacterial Causes of Bovine Mastitis. Veterinary Microbiology and Microbial Disease, 8th ed.; Mosby International Ltd.: London, UK, 2002; pp. 465-475.

37. Jagielski, T.; Gawor, J.; Bakuła, Z.; Decewicz, P.; Maciszewski, K.; Karnkowska, A. cytb as a new genetic marker for differentiation of Prototheca species. J. Clin. Microbiol. 2018, 56, e00584-18. [CrossRef]

38. Zhao, J.; Ghao, P.; Zhu, D. Optimization of $\mathrm{Zn}^{2+}$-containing mobile phase for simultaneous determination of kynurenine, kynurenic acid and tryptophan in human plasma by high performance liquid chromatography. J. Chromatogr. B 2010, 878, 603-608. [CrossRef]

39. Chen, Y.; Xie, Z.; Xiao, C.; Zhang, M.; Li, Z.; Xie, J.; Zhang, Y.; Zhao, X.; Zeng, P.; Mo, L.; et al. Peripheral kynurenine/tryptophan ratio is not a reliable marker of systemic indoleamine 2,3-dioxygenase: A lesson drawn from patients on hemodialysis. Oncotarget 2017, 8, 25261-25269. [CrossRef]

40. Plain, K.M.; de Silva, K.; Earl, J.; Begg, D.; Purdie, A.; Whittington, R.J. Indoleamine 2,3-Dioxygenase, Tryptophan Catabolism, and Mycobacterium avium subsp. paratuberculosis: A Model for Chronic Mycobacterial Infections. Infect. Immun. 2011, 79, 3821-3832. [CrossRef]

41. Sorgdrager, F.J.H.; Naudé, P.J.W.; Kema, I.P.; Nollen, E.A.; De Deyn, P.P. Tryptophan metabolism in inflammaging: From biomarker to therapeutic target. Front. Immunol. 2019, 10, 2565. [CrossRef]

42. Petzer, I.-M.; Karzis, J.; Donkin, E.F.; Webb, E.C.; Etter, E. Somatic cell count thresholds in composite and quarter milk samples as indicator of bovine intramammary infection status. Onderstepoort J. Veter. Res. 2017, 84, e1-e10. [CrossRef]

43. MacKenzie, C.R.; Worku, D.; Däubener, W. Regulation of Ido-Mediated Bacteriostasis in Macrophages: Role of Antibiotics and Anti-Inflammatory Agents. Adv. Exp. Med. Biol. 2003, 527, 67-76.

44. Bhutia, Y.D.; Babu, E.; Ganapathy, V. Interferon- $\gamma$ induces a tryptophan-selective amino acid transporter in human colonic epithelial cells and mouse dendritic cells. Biochim. Biophys. Acta Biomembr. 2015, 1848, 453-462. [CrossRef]

45. Dai, W.; Pan, H.; Kwok, O.; Dubey, J.P. Human indoleamine 2,3-dioxygenase inhibits Toxoplasma gondii growth in fibroblast cells. J. Interferon Res. 1994, 14, 313-317. [CrossRef]

46. Murr, C.; Widner, B.; Gerlach, D.; Werner-Felmayer, G.; Dierich, M.P.; Wachter, H.; Fuchs, D. Streptococcal erythrogenic toxins induce tryptophan degradation in human peripheral blood mononuclear cells. Int. Arch. Allergy Immunol. 1997, 114, $224-228$. [CrossRef] [PubMed]

47. Däubener, W.; MacKenzie, C.R. IFN-gamma activated indoleamine 2,3-dioxygenase activity in human cells is an antiparasitic and an antibacterial effector mechanism. Adv. Exp. Med. Biol. 1999, 467, 517-524.

48. Murr, C.; Gerlach, D.; Widner, B.; Dierich, M.P.; Fuchs, D. Neopterin production and tryptophan degradation in humans infected by Streptococcus pyogenes. Med. Microbiol. Immunol. 2001, 189, 161-163. [CrossRef]

49. Bortolotti, P.; Hennart, B.; Thieffry, C.; Jausions, G.; Faure, E.; Grandjean, T.; Thepaut, M.; Dessein, R.; Allorge, D.; Guery, B.P.; et al. Tryptophan catabolism in Pseudomonas aeruginosa and potential for inter-kingdom relationship. BMC Microbiol. 2016, 16, 137-147. [CrossRef] 
50. Klein, M.S.; Almstetter, M.F.; Nürnberger, N.; Sigl, G.; Gronwald, W.; Wiedemann, S.; Dettmer, K.; Oefner, P.J. Correlations between milk and plasma levels of amino and carboxylic acids in dairy cows. J. Proteome Res. 2013, 12, 5223-5232. [CrossRef]

51. Saito, K.; Markey, S.; Heyes, M. Effects of immune activation on quinolinic acid and neuroactive kynurenines in the mouse. Neuroscience 1992, 51, 25-39. [CrossRef] 